\title{
Childbearing dynamics among married women of reproductive age in Nigeria: re-affirming the role of education
}

\author{
"Stephen A. Adebowale ${ }^{1,2}$ and Martin E. Palamuleni ${ }^{1}$ \\ ${ }^{1}$ Population Training and Research Unit, Faculty of Humanities and Social Sciences, North-West \\ University, Mafikeng, South Africa.
}

${ }^{2}$ Department of Epidemiology and Medical Statistics, Faculty of Public Health, College of Medicine, University of Ibadan, Ibadan, Nigeria.

\begin{abstract}
Nigeria ranks among the high-fertility countries in sub-Saharan Africa. Studies that examine relationship between fertility dynamics and education are important to improving maternal and child health. This study uses 2008 NDHS dataset on births history of married women of childbearing age. Data were analysed using ANOVA, Kaplan-Meier and Cox-proportional hazard models. Mean CEB were 6.72 and 4.31 among women with no formal education and higher education respectively. Majority (38.6\%) of the women left 24-35 months births-interval. Women with lower education exhibited shorter births-interval and higher completed fertility than more educated women. The Births Progression Hazard Rate from marriage to $I^{\text {st }}$ birth was higher among highly educated women than those with no education, but reverse pattern was observed at higher order births. This pattern barely changes after controlling for other socio-demographic variables. Education remains an important factor in fertility dynamics in Nigeria; therefore, existing policies addressing female education should be sustained.
\end{abstract}

Keywords: Fertility, parity progression, births interval, education, Nigeria

\section{Résumé:}

Le Nigéria se range parmi les pays de haut-fertilité en Afrique sous-saharien. Les études qui examinent le rapport entre la dynamique de fertilité et l'éducation sont importantes pour l'amélioration maternelle et la santé enfantile. Cette étude emploie l'ensemble de données de 2008 NDHS sur l'histoire de naissances des femmes mariées de l'âge de grossesse. Des données ont été analysées en utilisant ANOVA, Kaplan-Meier et modèles Cox-proportionnels de risque. CEB moyens étaient 6.72 et 4.31 parmi des femmes sans l'enseignement conventionnel et l'éducation plus élevée respectivement. La majorité (38.6\%) des femmes a laissé $24-$ 35 mois de naissance-intervalle. Les femmes avec l'éducation inférieure ont exhibé un naissance-intervalle plus court et une fertilité réalisée plus élevée que les femmes plus instruites. Le taux de risque de progression de naissances du mariage à la lère naissance était plus haut parmi les femmes de haut niveau que ceux sans l'éducation, mais le modèle d'inverse $a$ été observé aux naissances évoluées. Ce modèle change à peine après contrôle pour d'autres variables socio-démographiques. L'éducation demeure un facteur important dans la dynamique de fertilité au Nigéria ; donc, des politiques existantes adressant l'éducation femelle devraient être soutenues.

Mot-clé: Fertilité, progression de parité, naissances intervalle, éducation, Nigéria

\section{Introduction}

Nigeria ranks among the high fertility countries in sub-Saharan Africa and one of the top-ten most populous countries globally (PRB, 20I2). High fertility is associated with poverty, maternal and child mortality (An-Magritt, 2010; Sajeda et al., 2007). Since postindependence, Nigerian governments have been trying to reduce the prevalence of disease and alleviate poverty. About five decades later, achievement of these aims still remains a mirage with key socio-economic and development indicators getting worse than they were at independence. For example, between 1962 and 1975, the average GDP growth rate and poverty rate were $9.4 \%$ and $48 \%$ respectively (Shamsudeen, 2010). In 2009, after a decade of democratic rule, the Nigerian economy has grown by an average of $7 \%$ and the poverty rate reduced to $50 \%$, from $70 \%$ in 1999 (Shamsudeen, 2010; UNDP, 2010). Although, reduction in demographic indicators such as fertility (TFR $=5.7$ births per woman), infant mortality (75 per 1000 live birth), under-five mortality ( 150 per 1000 live birth) and maternal mortality (545 per 100,000 live births) have been achieved so far, these indicators are high

*. Correspondence author: Adehamilt2008@yahoo.com; Phone: +23433565210 
compared to other developing nations in sub-Saharan Africa (PRB, 2012; National Population Commission and ICF Macro, 2009). The population growth rate is high and as a result the population doubles itself within two decades (PRB, 2012; National Population Commission and ICF Macro, 2009).

In response to the pattern of the population dynamics and its adverse effect on national development, the Federal Government of Nigeria approved the National Policy on Population for Development in 1988 and was reviewed in 2005 (NPC, 2004). The reviewed policy clearly aligns global targets such as programme of action of 1994 International Conference on Population and Development (ICPD) and theme of the Millennium Development Goals (MDGs) with local priorities. In the policy, the following targets were set: reduce the national population growth rate to 2 percent or lower by 2015 , reduce the Total Fertility Rate (TFR) by at least 0.6 children every five years by encouraging child spacing through the use of family planning, reduce the infant mortality rate to 35 per I,000 live births by 2015 , reduce the child mortality rate to 45 per I, 000 live births by 2010 , reduce the maternal mortality ratio to 125 per 100,000 live births by 2010 and to 75 by 2015 (NPC, 2004). A closer examination at these demographic indices shows a clear divergence between the policy priorities and its implementation, less than 3-years to 2015, virtually all the policy targets are yet to be accomplished and seems unrealizable (PRB, 2012; National Population Commission and ICF Macro, 2009). The challenges of the goals attainment are; high population growth rate, poverty and high illiteracy level.

In Nigeria, pregnancy related problems remain one of the most common causes of mortality and morbidity among children and women of reproductive age. Also, soaring fertility is the mechanism propelling the population growth. Women's educational attainment is widely known as having strong influence on mortality and morbidity associated with fertility and pregnancy (Kriti et al., 20I I; Ann, 2007). While researchers mainly focused on direct causes of childhood and maternal mortality, the patterns of birth spacing and parity progression associated with pregnancy are yet to be adequately explored in Nigeria. The objectives of this study are to determine the patterns of births interval, parity progression and completed fertility in Nigeria. It also examines factors influencing birth spacing and parity progression among which education is considered as the key independent variable. Information on birth spacing is essential for monitoring population growth and apart from advancing knowledge of fertility dynamics it also provides proper examinations of patterns and changes in the pace at which births of each order occur.

Studying the dynamics of birth spacing is of interest because inferences are consistent with the view that in some developing countries, couples with large families have shorter birth intervals than those with smaller families (Samuel et al., 20I I; Ho, 1994). This suggests that the short birth interval may be inversely related to completed fertility and has a significant bearing on maternal and child health as expressed by competition and maternal depletion hypotheses (Norton, 2005; Bicego and Ahmad, 1996). Recently, Demographers have given increasing attention to parity progression while studying fertility dynamics as a result of limitation of the methodologies involved in estimation of the conventional Total Fertility Rate (Bhardwaj, 2010). The idea builds on the fact that fertility rate should not only be measured using the current estimate with the assumption that the present age specific fertility schedule remains constant throughout the childbearing period. It was argued that the past fertility experience of a woman and the pace at which births occur should be an important factor to consider (Feeney and Wijeyesekera, 1983). This approach creates an avenue for full exploration of sequential and dynamic nature of the reproductive process. Consequently, we used birth interval as an indicator of childbearing dynamics in this paper.

\section{Literature review and theoretical framework}

The question on the link between women's education and fertility has received much attention in the literature (Anu and Praveen, 2013; Bbaale and Mpuga, 20I; Hossain, 1989; Bongaarts, 1978). Since the last decade of the $20^{\text {th }}$ century, many developing nations have adopted policies designed to reduce speedy population growth. Among all the policy alternatives, women's education is considered a highly effective means of lowering fertility and attainment of this goal (United Nations, 1995a; United Nations, 1995b). Data from different studies which introduce a number of socioeconomic controls to isolate an impact of education on fertility revealed a strong continued negative relation between female education and fertility (Bbaale and Mpuga, 20 I I; Anu and Praveen, 2013). The negative relationship between female education and fertility has also been described as "one of the most clear-cut correlations" in the social science literature (Cochrane, 1979). This suggests the dominant role of education on fertility.

The theoretical framework for this study is based on Henry (1972) where he found that couples exhibit a 'natural' rate of childbearing after marriage 
and they begin to increase the births interval at later parities if the socioeconomic condition which is widely known to be influenced by education becomes less favourable. The emergence of this form of parity-specific application of birth control over the marriage and life circles was also interpreted by Coale (1973) as an indicator of the onset of the demographic transition. Coale (1973) pointed out that cultural restraint on fertility would evolve from natural proximate determinants to control reproductive behaviour. Education has a strong influence on the proximate determinants of fertility (Hossain, 1989; Bongaarts, 1978).

The theoretical link between women's educational attainment and the timing of the first birth may be classified into proximate factors, economic, and cultural factors (Hossain, 1989; Bongaarts, 1978). The proximate effects operate mainly through variations in age at marriage and contraceptive usage. The economic factors involve the value and cost of children which may depend on the relative priority given to various possible life-pursuits while the cultural considerations include variations in norms and ideas on women's traditional roles as mothers and wives (Baschieri and Hinde, 2007; Westoff, 1992). The long years of formal education invariably delay a woman's entrance into marriage which indirectly increases the age at first birth (Westoff, 1992). Education also affects the age at first birth indirectly through the use of more effective contraception. In several studies in the developing world, the likelihood of contraceptive use has been found to be significantly higher among highly educated women (Addai, 1999; Khan and Rahman, 1997).

From an economic standpoint, education affects the timing of the first birth through changes in real and perceived costs and utilities of children (Kasardaetal, 1986; Maxwell, 1987). Economic theory provides an explanation that female schooling may increase the opportunity cost of childbearing and rearing (Becker, 198I; Schultz, 198I). The decision to have a child entails cost which educated women are better able to assess. Given the higher investment in education, the opportunity cost of leaving the labour market to become a mother is higher for educated women, which often results in the postponement of childbearing or forgoing it altogether as has been observed in some Western countries (RajuItonetal, 1990). Higher education also enhances opportunities that are alternative to childbearing e.g paid wages and participation in labour force. However, it has some implicit norms and values that are often incompatible with childbearing. With higher education, investment cost in children may also increase given the higher socio-economic and cultural aspirations for children of the better educated
(Dewit and Rajulton, 1992). Delays may thus follow from decisions to postpone childbearing until the woman feels sufficiently secured to provide for her children (Dewit and Rajulton, 1992).

Culturally, attendance of school takes girls out of the domestic environment and offers literacy and exposure to new ideas that may compete with traditional customs that promote early marriages, early childbearing and short births interval (Westoff, 1992). By exposing women to non-traditional roles and providing them with the means to establish viable alternatives to motherhood, education expands women's life choices. The primary effect of education on the timing of births before and after marriage may thus relate to the development of value orientations that favour personal fulfilment over more traditional roles or marriage and childbearing. Where educated women perceive childbearing as incompatible with attaining personal goals and ambitions, childbearing is likely to be delayed or postponed altogether (Alaka, 2002; Caldwell, 1980).

Hawthorn (1970) developed a framework for "explaining human fertility" that included economic, cultural and technological factors. He opined that the manner and pace at which people bear children cannot be easily understood from one perspective and that a multi-dimensional approach is necessary. At the societal level, the institutions that are needed to ensure the continued survival of the population require the investment of substantial cultural, economic and political resources (Hawthorn, 1970). In support of this opinion, Lesthaeghe and Surkyn (1988) found that the demand for children, regardless of whether it is conscious or unconscious, is very closely associated with the ways people make a living, their aspiration, identities, their past, and the likely futures they envision.

Most theories of childbearing indicate that an increase in a woman's birth parity is determined by social and economic factors. However, according to Davis and Blake (1956), the influence of these factors is not direct. Rather, three biological processes that occur in sequence mediate it; intercourse, conception, and gestation. In support of this view, Davis and Blake provided a list of variables that are affected by cultural norms and socioeconomic conditions, on the one hand, and which affect the probabilities of intercourse, conception, and gestation, on the other. Modification to this was provided by Bongaart, (1978). He observed that socioeconomic and cultural factors which influence childbearing operates through proximate determinants and changes in fertility are direct result of changes in these determinants which thus mediate the effect of changes in social, economic and cultural factors. Female schooling may also affect fertility through knowledge and 
more effective use of contraceptive methods (Rosenzweig and Schultz, 1985; 1989) or by increasing female autonomy and bargaining power in fertility decisions (Mason, 1986). Education may lower fertility through improvements in child health and reduced rates of child mortality as women need to have fewer births to yield the same desired family size (Lam and Duryea, 1999).

The economic, structural, and cultural theories shed more light into the dynamics of childbearing. For instance, in Becker (1982) quality of children theory where he propounded that in traditional societies large families were universally desired. Thus, as family income increases, the number of children was also likely to increase. However, in modern industrial societies, reproduction has come to involve a considerable expenditure of time and other resources. Another widely used economic approach is Easterlin's theory of relative income (Easterlin, 1978). Easterlin argues that the effect of income on family size depends on how couples view their current income with respect to their demand for child quality. However, Caldwell (1980) in his theory proposes that in every society fertility decisions are economic rational responses to family net wealth flows which could be upward or downward. Upward net flows are situations where wealth is being transferred from younger to older generations, and individual interests are dominated by community interests. Downward wealth flows on the other hand is a circumstance where parents are expected to provide for children's economic well-being (Caldwell, 1980). In societies with net upward wealth flows, Caldwell said that the economic rational decision of couples with respect to childbearing may be to have as many children as possible, because having additional child will contribute positively to a parent's wealth, security in old age and lead to improvement in their social and political well-being (Caldwell, 1980). On the other hand, in societies with net downward wealth flows, the economically rational decision is to have no children or the minimum number allowed by a psychological disposition that derives pleasure from children and parenting (Caldwell, 1980). Caldwell (1980) further claimed that the worldwide transition from high to low fertility is the result of a change in family structures from upward to downward wealth flows. Other important theories of the family building processes includes diffusion theories, supply-demand theory etc.

Nigeria is among the countries with high burden of number of people living with HIV/AIDS (PRB, 2012; UNAIDS, 20I I). Socio-economic factors influence HIV/AIDS and fertility through an overlapping set of proximate determinants. Initial evidence from Uganda suggests that the infection may lead to lower fertility because women of childbearing age are mostly affected by the disease (Ntozi et al., 200I). The argument is that the increase adult and childhood mortality due to AIDS in some countries of sub-Saharan Africa could lead couples to be conscious of the need to limit childbearing. In a study done in Zimbabwe, it was revealed that HIV infected women would prefer to limit childbearing due to the concern about their own mortality and its effect on children (Grieseretal, 200I). On the other hand fear of dying of AIDS or losing a child to the disease may increase at least on the short run. Therefore, young people who perceive that they may contract HIV or die of AIDS related diseases may decide to marry early and have children as soon as possible.

\section{Data and methods}

\section{Study design, data source and variables identification:}

The study utilized 2008 Nigeria Demographic Health and Survey dataset collected by National Population Commission (Nigeria) and ICF Macro Calverton, Maryland, USA. The 2008 NDHS was implemented by the National Population Commission and fielded from June to October 2008. The survey was designed to allow reliable estimation of fertility. The population covered was women age 15-49 years. The data was accessed on the web platform of measure DHS (http://www.measuredhs.com/). Interested readers should visit the website for more information on the sampling procedures, pre-test, recruitment of study participants and validation of the study instruments. In the original sample, 33,385 women aged 15-49 were interviewed. Our study focused on ever married women of childbearing age who started childbearing immediately after marriage. Thus, those who had premarital births and women who had multiple births were excluded from the study. This reduces the number of subjects in this study to 19,622 . Since cluster sampling was used for the data collection, the data was weighted to account for the study population subjects who were outside the cluster demarcation areas and represeantativness. Data analysis was based on the births history of women and parity progression analysis was limited to the first seven births.

We did not analyse the parity progression probability for higher order births $(8+)$ due to few births reported at parity 8 and above. Stopping at the $7^{\text {th }}$ birth reflects and encompasses the total fertility rate of Nigeria which is known to be 5.7 (National Population Commission and ICF Macro, 2009). Chisquare test was used to examine the association between the births interval and independent variables such as age, place residence, education, region, 
religion, wealth index, ethnicity, age at first birth, age at first marriage, number of marital union and survival status of the preceding child.

\section{Variable description}

\section{Births interval}

Births interval $(0-17=1 ; 18-23=2 ; 24-35=3 ; 36-59$; $60+)$ defined as the time in months between two consecutive births is the key dependent variable in this study. This was used to measure how women included in this study were progressing from marriage to first birth and from first birth to higher order births.

\section{Education}

The independent variable of interest is level of education of women. Education is one of the socioeconomic characteristics that have influence on other aspects of life including fertility. For instance, education has influence on timing and spacing of childbearing both as a direct determinant of behaviour and indirectly as it affects cultural attitudes and gender relations (Bbaale and Mpuga, 20I; Hossain, 1989; Bongaarts, 1978). It is worthwhile to argue that if a woman is educated, her perception and attitudes to the control of her fertility may be different from her counterparts without formal or less education. In this study, education was categorized as; none $=0$, primary $=\mathrm{I}$, secondary $=2$ and higher $=3$.

\section{Place of residence}

In this study, place of residence was categorized as urban $=I$ and rural $=2$. The type of place of residence has implication on childbearing dynamics in terms of access to public health information and facilities that are promoting fertility reduction. Some socio-economic characteristics like being educated, family planning information on media, that can also facilitate low fertility are more common in urban areas than rural areas.

\section{Region}

Nigeria is made up of 36 states and a Federal Capital Territory (FCT), divided into six regions based on geographical distribution of its population. These are North Central $=$ I, North East $=2$, North West $=3$, South East $=4$, South South $=5$, and South West $=6$. The North East, North West and some parts of North Central regions are predominantly Hausas', while South West are Yoruba speaking people, South East and South South are mostly people of Igbos' and ljaw origin respectively.

\section{Current age}

Age is the number of complete years lived since birth. Age is a biological characteristics and it varies.
It is the changing nature of age that creates such a dynamic process because younger people are treated differently from the older people, and different kinds of sexual behaviour are expected of people as they move through different ages. For instance, in the teen years, reproductive hormones influence behaviour which women exhibit at those ages. The data were restricted to women of childbearing age because their fertility experience is still recent and this group of women is more vulnerable to childbearing activities. While those women who are above 49 years are assumed to be menopausal, those below $15 y e a r s$ are not sexually active. Age was categorized in this study as $15-19=1,20-24=2,25$ $29=3,30-34=4,35-39=5,40-44=6,45-49=7$.

\section{Age at first marriage}

Marriage is the union or solemnization of woman and man, where the two live together as husband and wife. It signifies the initiation of process of childbearing, as people would expect the new couple to have a baby after nine months or at most a year after marriage. Age at first marriage largely influences exposure to childbearing risks.

\section{Age at first birth}

One of the factors that determine fertility levels in a population is the average age at first birth. Women who marry early are typically exposed to pregnancy for a longer period. Thus, early childbearing generally leads to a large family size and is often associated with increased health risks for the mother and child. A rise in the mean age at first birth is typically a sign of transition to lower fertility levels. The age at which childbearing commences is an important determinant of the overall level of fertility.

\section{Number of marital unions}

In Nigeria, it is not culturally acceptable for a married woman to live either as a single parent or as a divorcee. These situations are not a common phenomenon in Nigeria. However, personal influence, persuasion or financial interest, widowhood may be associated with number of union. The number of marital union has implications on the number of children a woman bears including timing and spacing of such births. For instance, a woman who had had her desired number of children in her previous marriage may be tempted to bear more children in her new union.

\section{Religion}

Religion is an organized collection of beliefs, cultural systems, and world views that relate humanity to an order of existence. Religion is one of ways of life in any settings across the world and plays an influential role in fertility when three conditions are fulfilled: 
first, the religion articulates behavioral norms with a bearing on fertility behavior; second, the religion holds the means to communicate these values and promote compliance; and, third, religion forms a central component of the social identity of its followers (McQuillan, 2004). The three key religions in Nigeria (Islam, Christian and Muslim) frown at abortion and divorce and these may have implications on the timing of births.

\section{Wealth index}

The standard distinctions in fertility research are: demand for children, deliberate fertility regulation or motivation to regulate fertility and the costs of regulation. In Nigeria, the costs of fertility regulation a times include financial costs; hence, one may theorize that being wealthy will increase the success in fertility aspirations. It enhances the accessibility and affordability of family planning services. Wealth index was used as a proxy for measuring the long-term standard of living and its computation was based on data from the household's ownership of consumer goods; dwelling characteristics; type of drinking water source; toilet facilities; and other characteristics that are related to a household's socioeconomic status (National Population Commission and ICF Macro, 2009). To construct the index, each of these assets was assigned a weight (factor score) generated through principal component analysis, and the resulting asset scores were standardized in relation to a standard normal distribution with a mean of zero and standard deviation of one (Gwatkin et al., 2000). Each household was then assigned a score for each asset, and the scores were summed for each household. Individuals were ranked according to the total score of the household in which they resided. The aggregate score was therefore disentangled into five categories as poorest, poorer, middle, richer and richest (National Population Commission and ICF Macro, 2009).

\section{Ethnicity}

There are about 374 identifiable ethnic groups in Nigeria, with the Igbo, Hausa, and Yoruba as major groups. Ethnicity is categorized in the present study as; Hausa $=1$, Igbo $=2$, Yoruba $=3$ and others $=4$.
People in each of these three ethnic groups have similar cultural identities which they uphold despite modernization and improvement in level of education across the country. The differential in cultural identities in each of the three key ethnic groups in Nigeria has the potential to influence fertility dynamics. For instance, the study by Konia (2003) shows that in Nigeria, fertility differentials by ethnicity remain, even after controlling for selected socioeconomic and demographic variables.

\section{Survival status of the preceding child}

If a baby dies shortly after birth, the mother has the tendency to reduce her intended birth interval as a result of the need to replace the lost child, thus increasing the size of her children ever born. As an example, a study in Zimbabwe shows that there is a replacement effect in the relationship between child survival and fertility independent of individual characteristics of women (Udjo, 1997). We categorized this variable as " $\mathrm{No}=\mathrm{l}$ " if the preceding child is dead and "yes=2" if he/she is alive.

\section{Estimation of mean duration of births interval and completed fertility}

Mean birth interval and completed fertility were estimated using analysis of variance. Mean instead of median was used as summary statistics for births interval because the intervals between successive births were found to be normally distributed and as such the distribution is known. On the other hand, the estimation of completed fertility defined as the cumulative fertility until the date when all members of the cohort have reached the end of the reproductive period was restricted to women aged 45-49 years. This is because women in age group 45-49 years are expected to have completed childbearing either as a result of being menopausal or sterilized or are satisfied with the number of children they already have.

\section{Estimation of parity progression probabilities}

Kaplan-Meier (K-M) method was used to estimate the parity progression probabilities obtained in this study. Different time origins $t_{0}$ were defined for each of the child birth process. These are:

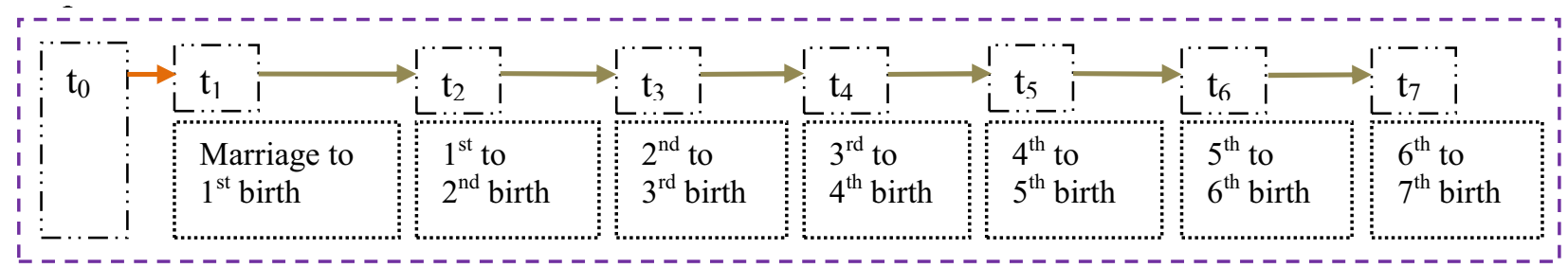

Source: Adebowale and Palamuleni, 2013

The initial period starts at $t_{0}$ (Time of Marriage) and ends just before $t_{(I)}$ (First Birth), etc. Suppose there 
are $\mathrm{k}$ such intervals and suppose there are $\mathrm{n}$ individuals with observed survival times $t_{1}, t_{2}, \ldots, t_{n}$ of which some are censored and that there may be more than one woman with thesame observed survival times; so we have $r$ births with $r \leq n$ and with ordered survival times $t_{1}<t_{2}<\ldots<t_{r}$ The $j$-th birth is at time $t_{j}$ and let the number of women at $t_{j}$ including those about to give birth at $t_{j}$ be $n_{j}$. Therefore, the total number of births at $t_{j}$ is $b_{j}$. Consider the time interval $t_{j}$ - $\delta$ where $\delta$ is very small.

The probability of survival through this interval is $\left(n_{j}-b_{j}\right) / n_{j}$. If the censored survival time occurs at the same time with a birth time, the censored time is taken to occur immediately after the time of birth. There are no other births between $t_{j}$ to $t_{j+1}-\delta$, so the probability of surviving through this interval is $I$. Thus, the joint probabilities of surviving from $t_{j}-\delta$ to $t_{j}$ and from $t_{j}$ to $t_{j+1}-\delta$ were estimated by $\left(n_{j}-b_{j}\right) / n_{j}$ as $\delta$ tends to zero. The model $\left(n_{j}-b_{j}\right) / n_{j}$ produces an estimate of the probability of surviving from $t_{j}$ to $t_{j+1}$ without giving birth, thus generating K-M survival function

$$
\mathrm{S}(\mathrm{t})=\prod_{\mathrm{j}=1}^{\mathrm{k}}\left(1-\frac{\mathrm{b}_{\mathrm{j}}}{\mathrm{n}_{\mathrm{j}}}\right)
$$

\section{Multivariate analysis}

The basic model used for this study is the proportion hazards model proposed by Cox in 1972. It is also known as the Cox regression model and based on the assumption of proportional hazards. Since it does not assume any particular form of distribution for survival times, it is referred to as a semi-parametric model. Proportional hazard is the ratio of the hazards for two subjects' $j$ and $k$ at time $t$ is the same for all values of $t$, i.e. ${ }_{i}(t) / h_{j}(t)=\psi$ for $t \geq$ $\psi$ is a constant and $\psi>0$.

If $\psi<\mathrm{I}$, the hazard of progressing to the next birth at time $t$ is smaller for an individual and greater if $\psi>\mathrm{I}$, compared to the reference category where $\psi=\mathrm{I}$.Since $\psi>0$, set $\psi=\beta$. Therefore; $\beta=\psi \log$ (log of the hazard ratio). In such situation, any value of $\beta$ in the range $(-\propto, \propto)$ will make $\psi$ positive. $h_{i}(t)=h_{j}(t) \exp (\beta)$. In this study, there are 19, 622 women with information relevant for the achievement of the study objectives. Let $h_{i}(t)$ be the hazard of the $i$-th subject at time $t$ and let $X$ be an indicator variable such that $x=I$ if a woman has given birth to a child of specific order over an interval and $x=0$ if otherwise. If $x_{i}$ is the value of $x$ for the $i$-th woman in the study then: $h_{i}(t)=h_{0}(t) \exp \left(\beta x_{i}\right)$.

We assumed that the hazard of giving birth at a particular time depends on the values $x^{1}, x_{2}, \ldots, x_{p}$ of $p$ explanatory variables recorded after marriage or having the previous birth. Let $\underline{X}$ be a vector representing the set of the $p$ explanatory variables, so that $X=\left(x_{1}, x_{2}, \ldots, x_{p}\right)$. Let $h_{0}(t)$ be the hazard function for an individual woman for whom the values of all the $p$ explanatory variables are zero. Therefore; for the $\mathrm{i}$-th individual the hazard function is $h_{i}(t)$ $=\psi\left(\underline{x}_{i}\right) h_{0}(t)$. Where $\psi\left(x_{i}\right)$ is a function of the explanatory variables for the $\mathrm{i}$-th woman and this is interpreted as the hazard at time $\mathrm{t}$ for an individual whose vector of explanatory variables is $\underline{x}_{i}$, relative to the hazard for an individual for whom $\underline{x}=0$.This produces a linear model for the logarithm of the hazard ratio.

$\log \left\{\mathrm{h}_{\mathrm{i}}(\mathrm{t}) / \mathrm{h}_{0}(\mathrm{t})\right\}=\beta_{1} \mathrm{x}_{1 \mathrm{i}}+\beta_{2} \mathrm{x}_{2 \mathrm{i}}+\ldots+\beta_{\mathrm{p}} \mathrm{x}_{\mathrm{pi}}$

$=\sum_{\mathrm{j}=1}^{\mathrm{p}} \beta_{\mathrm{j}} \mathrm{x}_{\mathrm{ji}}$

Note: We have not made any assumption concerning the actual form of $h_{0}(t)$ the baseline hazard function. This is because it is not of primary interest and it is not necessary to substitute for it in order to estimate the $\beta$-coefficients. Thus the model is non-parametric with respect to time but parametric in terms of the exploratory variables $\left(\mathrm{x}_{1}, \mathrm{x}_{2}, \ldots, \mathrm{x}_{\mathrm{p}}\right)$; and is thus 'semiparametric'. The explanatory variables are; age, residence, education, region, religion, wealth index, ethnicity, age at first birth, age at first marriage, number of marital unions and survival status of the preceding child. The inclusion of these variables is a result of their relationship with timing of birth as expressed under variable description above.

\section{Results}

The data as shown in Figure I show that the mean children ever born diminishes as the level of education increases. It reduces from 6.72 among women with no formal education to $4.3 \mathrm{I}$ among women with higher education. The mean CEB of married women in Nigeria was 6.17 children. 
Figure 1: Bar Chart of the Mean Children Ever Born by Married Women according to Level of Education, NDHS, 2008

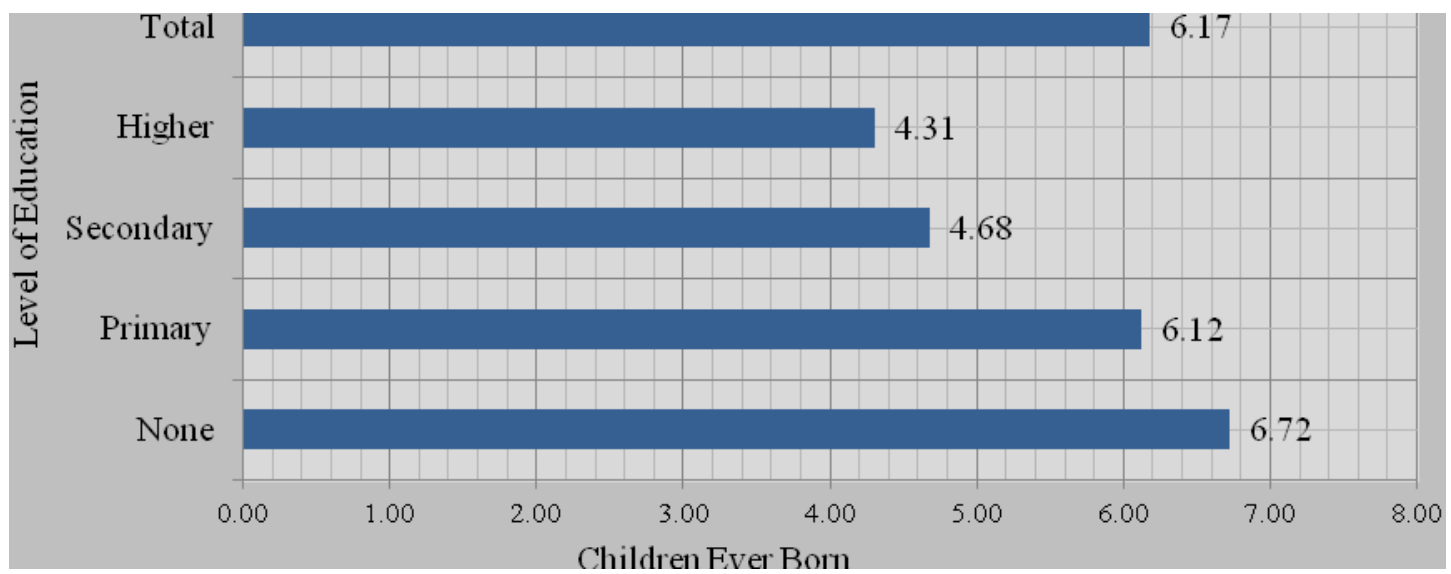

The data as shown in Table I show that the mean births interval was $32.2 \pm 18.5$ months, majority of the women $(38.6 \%)$ left $24-35$ months interval between two consecutive births and $22.3 \%$ left 36 60 months births interval. Also, the mean births interval was significantly higher among older women than the younger women and the mean completed fertility for all the women included in this study was $8.5 \pm 2.7$. For instance, $9.0 \%$ and $8.6 \%$ of women in age group 40-44 and 45-49 years respectively left above 60 months interval between births as against only $1.7 \%$ of women in age group 15-24 years. The mean births interval was highest among women residence in the southwest Nigeria $(37.7 \pm 21.4)$ and least among their counterparts residing in the south east (30.4 \pm 17.3$)$ and north east (30.4 \pm 17.3$)$.Also, short birth interval (less than 18 years) was more common among women in the North East (14.3\%), North West (13.9\%), South East (13.6\%) and south south(12.8\%). The completed fertility was highest in the North West $(9.4 \pm 2.7)$ and least in the south west $(6.4 \pm 2.1)$. Although, the pattern of births interval between rural and urban women was similar but the data is evidenced that higher births interval and lower completed fertility were reported among the urban women than their rural counterparts.

As regards the level of education, the mean births interval increases consistently as the level of education increases. It increases from $31.4 \pm 18$.I among women with no formal education through $35.1 \pm 21.2$ among women with higher education. While majority of the women in lower education categories exhibited shorter birth interval, the more educated women were more prominent at leaving longer interval between births. Also, the pattern of interval 24-35 years was similar across all the level of education except women in higher level education (36.6\%) which show a slight disparity at this interval. It is important to know that striking disparity exist between the completed fertility as measured by children ever born of women who had no formal education $(8.9 \pm 2.7)$ and those with higher level of education $(5.8 \pm 2.4)$.According to religion, the pattern of births interval was similar among the catholic women and Muslim women but differs between the Muslims and women in other Christian religious denomination. For instance, the mean births interval for Catholic and Muslim women was 31.9 17.6 and $31.4 \pm 18.0$ respectively whereas it was $33.9 \pm 19.5$ for women in other Christian religious denominations. However, the highest completed fertility was reported by Muslim women $(9.1 \pm 2.7)$ which was higher than women who belong to traditional religious group $(8.1 \pm 2.3)$ but the least number was found among women in other Christian religious group $(7.5 \pm 2.5)$.

The wealth index used in this study serves as a proxy for measuring the long-term standard of living. It was based on data from the household's ownership of consumer goods; dwelling characteristics; type of drinking water source; toilet facilities; and other characteristics that are related to a household's socio-economic status. To construct the index, each of these assets was assigned a weight generated through principal component analysis, and the resulting asset scores were standardised in relation to a standard normal distribution with a mean of zero and standard deviation of one (Gwatkin et al., 2000). Each household was then assigned a score for each asset, and the scores were summed for each household. Individuals were ranked according to the total score of the household in which they resided. 
The sample was then divided into quintiles from one (lowest) to five (highest) (National Population Commission and ICF Macro, 2009). The data further revealed that women in higher wealth quintile left longer birth interval than those in the lower wealth quintile. For instance, the proportion of women in the poorest wealth quintile who left births interval $<18$ and $18-23$ months was 13.4 and 21.7 respectively as against 10.4 and 17.5 of women in the highest wealth quintile. The mean births interval increases consistently with increase in wealth quintile. It increases from 31.4 18.4 months among women in poorest wealth quintile to $35.0 \pm 20.8$ among their counterparts in the richest wealth quintile. In terms of completed fertility, the reported figure was highest among women in the poorest wealth quintile $(9.0 \pm 2.6)$ and least among those in the richest $(6.4 \pm 2.3)$. The data also depict that Yoruba ethnic group were more in habit of leaving longer births between two consecutive children than any other religious groups in Nigeria. This reflects in the gap between the mean birth interval of Yoruba $(38.0 \pm 21.5)$ ethnic group which was strikingly higher than Hausa (30.9 \pm 17.8$)$ and lgbo (30.8 \pm I7.5) ethnic diversity. It is also important to note that the completed fertility of Yoruba women $(6.2 \pm 2.0)$ was significantly lower than that of Hausa $(9.6 \pm 2.6)$ and lgbo $(7.7 \pm 2.3)$ women. The distribution of births interval and completed fertility with respect to age at first birth, age at first marriage, and preceding child survival status follow the expected pattern (Table I).

Table I Percentage distribution of births interval, mean births interval, mean completed fertility of married women according to socio-demographic characteristics, NDHS 2008

\begin{tabular}{|c|c|c|c|c|c|c|c|c|}
\hline \multirow{2}{*}{$\begin{array}{l}\text { Background } \\
\text { Variables }\end{array}$} & \multicolumn{5}{|c|}{ Births Interval } & \multirow[t]{2}{*}{ Total Births } & \multirow{2}{*}{$\begin{array}{l}\text { Mean } \\
\text { Birth Int. }\end{array}$} & \multirow{2}{*}{$\begin{array}{l}\text { Mean } \\
\text { C.F }\end{array}$} \\
\hline & 17 & $18-23$ & $24-35$ & $36-60$ & $61+$ & & & \\
\hline Total & 12.4 & 20.2 & 38.6 & 22.3 & 6.5 & 60489 & $32.2 \pm 18.5$ & $8.5 \pm 2.7$ \\
\hline \multicolumn{9}{|l|}{ Age* } \\
\hline $15-24$ & 13.4 & 20.5 & 44.4 & 19.9 & 1.7 & 3670 & $28.5 \pm 11.2$ & N.A \\
\hline $25-29$ & 11.8 & 20.8 & 41.1 & 22.9 & 3.4 & 9738 & $30.3 \pm 13.5$ & N.A \\
\hline $30-34$ & 12.9 & 20.0 & 38.5 & 23.3 & 5.2 & 11796 & $31.3 \pm 15.8$ & N.A \\
\hline $35-39$ & 12.7 & 19.6 & 37.6 & 22.8 & 7.3 & 13335 & $32.7 \pm 18.8$ & N.A \\
\hline $40-44$ & 12.1 & 19.4 & 36.7 & 22.8 & 9.0 & 11044 & $34.1 \pm 21.2$ & N.A \\
\hline $45-49$ & 11.8 & 21.3 & 37.7 & 20.5 & 8.6 & 10906 & $33.8 \pm 22.7$ & $8.5 \pm 2.7$ \\
\hline \multicolumn{9}{|l|}{ Region* } \\
\hline North Central & 9.3 & 19.0 & 39.7 & 24.8 & 7.2 & 10762 & $33.6 \pm 18.4$ & $7.9 \pm 2.3$ \\
\hline North East & 14.3 & 21.9 & 39.2 & 19.8 & 4.7 & 14772 & $30.4 \pm 17.3$ & $9.3 \pm 2.7$ \\
\hline North West & 13.9 & 21.7 & 38.3 & 20.4 & 5.7 & 17674 & $31.1 \pm 17.8$ & $9.4 \pm 2.7$ \\
\hline South East & 13.6 & 23.2 & 39.0 & 19.1 & 5.1 & 4809 & $30.4 \pm 17.1$ & $7.8 \pm 2.4$ \\
\hline South South & 12.8 & 18.2 & 37.8 & 23.5 & 7.8 & 5785 & $33.2 \pm 19.4$ & $7.8 \pm 2.4$ \\
\hline South West & 7.8 & 14.1 & 36.8 & 30.3 & 11.0 & 6687 & $37.7 \pm 21.4$ & $6.4 \pm 2.1$ \\
\hline \multicolumn{9}{|l|}{ Residence* } \\
\hline Urban & 11.4 & 18.9 & 38.9 & 23.4 & 7.5 & 14900 & $33.3 \pm 19.5$ & $7.7 \pm 2.7$ \\
\hline Rural & 12.7 & 20.6 & 38.5 & 22.0 & 6.1 & 45589 & $31.9 \pm 18.1$ & $8.7 \pm 2.7$ \\
\hline \multicolumn{9}{|l|}{ Education* } \\
\hline No education & 13.2 & 21.5 & 38.6 & 20.8 & 5.8 & 34950 & $31.4 \pm 18.1$ & $8.9 \pm 2.7$ \\
\hline Primary & 11.7 & 19.1 & 38.9 & 23.8 & 6.5 & 14082 & $32.5 \pm 17.8$ & $8.0 \pm 2.5$ \\
\hline Secondary & 10.6 & 17.3 & 38.6 & 25.3 & 8.1 & 9105 & $34.2 \pm 19.8$ & $6.7 \pm 2.1$ \\
\hline Higher & II.I & 18.2 & 36.6 & 24.3 & 9.7 & 2352 & $35.1 \pm 21.2$ & $5.8 \pm 2.4$ \\
\hline \multicolumn{9}{|l|}{ Religion* } \\
\hline Catholic & 12.1 & 20.7 & 39.2 & 22.0 & 6.0 & 4897 & $31.9 \pm 17.6$ & $7.8 \pm 2.2$ \\
\hline Other Xtian & 10.7 & 18.4 & 38.0 & 24.9 & 8.0 & 18064 & $33.9 \pm 19.5$ & $7.5 \pm 2.5$ \\
\hline Islam & 13.3 & 21.0 & 38.8 & 21.2 & 5.7 & 35743 & $31.4 \pm 18.0$ & $9.1 \pm 2.7$ \\
\hline Traditionalist & 11.5 & 22.7 & 38.2 & 21.3 & 6.4 & 1287 & $31.8 \pm 17.9$ & $8.1 \pm 2.3$ \\
\hline Other & 11.8 & 11.8 & 47.3 & 17.2 & 11.8 & 93 & $37.2 \pm 23.6$ & $7.9 \pm 2.4$ \\
\hline \multicolumn{9}{|l|}{ Wealth index* } \\
\hline Poorest & 13.4 & 21.7 & 38.2 & 20.6 & 6.0 & 17050 & $31.4 \pm 18.4$ & $9.0 \pm 2.6$ \\
\hline
\end{tabular}




\begin{tabular}{|c|c|c|c|c|c|c|c|c|}
\hline Poorer & 12.7 & 21.4 & 38.9 & 21.5 & 5.5 & 15086 & $31.3 \pm 17.2$ & $9.1 \pm 2.7$ \\
\hline Middle & 12.4 & 19.4 & 39.1 & 22.9 & 6.2 & 11844 & $32.2 \pm 18.3$ & $8.3 \pm 2.6$ \\
\hline Richer & 11.3 & 18.6 & 39.0 & 24.2 & 6.9 & 9366 & $33.2 \pm 18.5$ & $7.9 \pm 2.6$ \\
\hline Richest & 10.4 & 17.5 & 37.9 & 24.8 & 9.3 & 7143 & $35.0 \pm 20.8$ & $6.4 \pm 2.3$ \\
\hline \multicolumn{9}{|l|}{ Ethnicity* } \\
\hline Hausa & 13.9 & 21.7 & 39.2 & 19.8 & 5.4 & 17732 & $30.9 \pm 17.8$ & $9.6 \pm 2.6$ \\
\hline Igbo & 13.3 & 22.6 & 39.1 & 19.5 & 5.5 & 5933 & $30.8 \pm 17.5$ & $7.7 \pm 2.3$ \\
\hline Yoruba & 7.5 & 13.9 & 36.7 & 30.5 & 11.5 & 6305 & $38.0 \pm 21.5$ & $6.2 \pm 2.0$ \\
\hline Others & 12.3 & 20.2 & 38.6 & 22.7 & 6.3 & 30519 & $32.1 \pm 18.1$ & $8.5 \pm 2.6$ \\
\hline \multicolumn{9}{|c|}{ Age at first birth* } \\
\hline less than 18 & 13.0 & 20.5 & 38.4 & 21.7 & 6.4 & 28062 & $32.0 \pm 18.8$ & $9.5 \pm 2.6$ \\
\hline $18-24$ & 11.6 & 19.8 & 39.0 & 23.1 & 6.6 & 27383 & $32.6 \pm 18.3$ & $8.2 \pm 2.5$ \\
\hline $25-29$ & 13.3 & 20.1 & 38.4 & 22.2 & 6.0 & 4250 & $31.7 \pm 17.0$ & $6.8 \pm 2.3$ \\
\hline $30+$ & 13.7 & 24.6 & 36.4 & 20.4 & 4.9 & 794 & $30.2 \pm 15.6$ & $5.2 \pm 2.3$ \\
\hline \multicolumn{9}{|c|}{ Age at first marriage* } \\
\hline less than 18 & 12.9 & 20.8 & 38.4 & 21.6 & 6.3 & 42578 & $31.9 \pm 18.6$ & $9.1 \pm 2.6$ \\
\hline $18-24$ & 10.9 & 18.5 & 39.1 & 24.4 & 7.1 & 15587 & $33.2 \pm 18.4$ & $7.3 \pm 2.4$ \\
\hline $25+$ & 12.0 & 21.3 & 38.4 & 22.4 & 5.9 & 2323 & $31.6 \pm 16.3$ & $5.8 \pm 2.1$ \\
\hline \multicolumn{9}{|c|}{ Number of times married $*$} \\
\hline Once & 12.2 & 20.2 & 39.0 & 22.4 & 6.2 & 50067 & $32.0 \pm 17.9$ & $8.5 \pm 2.7$ \\
\hline $2+$ & 13.3 & 20.4 & 36.6 & 21.9 & 7.9 & 10169 & $33.2 \pm 21.2$ & $8.5 \pm 2.7$ \\
\hline \multicolumn{9}{|c|}{ Survival status of the preceding child* } \\
\hline No & 21.3 & 25.0 & 37.2 & 13.9 & 2.6 & 11322 & $26.8 \pm 14.2$ & $9.4 \pm 2.6$ \\
\hline Yes & 10.3 & 19.1 & 38.9 & 24.3 & 7.4 & 49167 & $33.5 \pm 19.1$ & $8.2 \pm 2.7$ \\
\hline
\end{tabular}

*Significant at 0.1\%; N.A: Not applicable because women in the group are still bearing children

Figure 2: Cumulative Parity Progression Probability of Married Women according to Parity by Levels of Education: NDHS, 2008

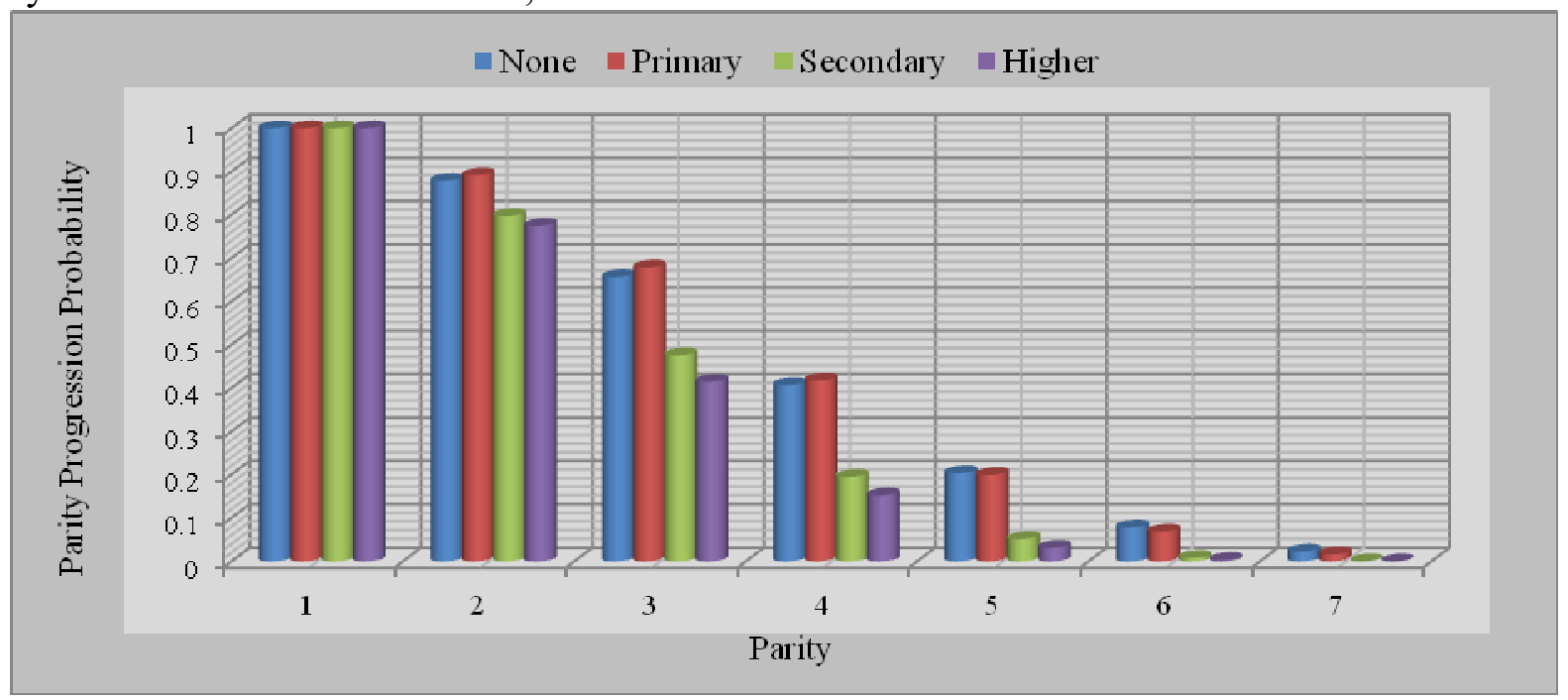

In Figure 2, the data show that the cumulative Parity Progression Probability (PPP) was consistently lower among married women with at least secondary education than their counterparts with either primary or no formal education. Parity progression probability from marriage to first birth was 1.0 as all the women included in the analysis had at least one birth. The gap in PPP between levels of education became pronounced at second and higher order births. The pattern of PPP was similar for all births order with women who had primary education progressing at the fastest rate up to the fourth birth order while 
those with no formal education were the fastest for births order five and above. Across all births order, married women with higher education progressed in childbearing at the least rate. The margin was wider at $3^{\text {rd }}$ births through higher order births.

Table 2 presents the hazard rate of progression from marriage to first birth and other higher order births. In the table, the data show that the hazard of progressing to first birth after marriage was higher among women with higher education $(H R=I .123$, $\mathrm{p}<0.0 \mathrm{I})$ than those with no education but the hazard rate of progressing to first birth after marriage was lower for women with primary education $(H R=0.95 I ; p<0.0 I)$ than those with no formal education. At higher order births, beginning from $2^{\text {nd }}$ to $3^{\text {rd }}$ and higher order births, the hazard rate was consistently lower among women with secondary and higher education. As an example, the hazard of progressing from $4^{\text {th }}$ birth to $5^{\text {th }}$ birth was $0.903(p<0.05)$ and $0.747(p<0.05)$ lower among women with secondary and higher education respectively than those with no formal education. While women from Yoruba ethnic group progressed at higher hazard rate to first birth (1.095; $p<0.05)$, the rate was significantly lower for $2^{\text {nd }}$ birth and higher order births than Hausa women.

It is surprising that hazard of progressing to $2^{\text {nd }}$ and higher order births was lower among women who had married more than once than those who had only married once. Compare with women in the north central, the hazard of progressing from the $2^{\text {nd }}$ to higher order births was consistently and significantly higher for women in the north east and north west region, but lower for women in the south west. For instance, among women in the south west, the hazard rate of progressing from $4^{\text {th }}$ to $5^{\text {th }}$ birth was $0.875(p<0.05)$ lower relative to women in the north central part of Nigeria and the hazard rate reduces constantly for higher order births.

The multivariate result is also show that hazard of progressing from $1^{\text {st }}$ to $2^{\text {nd }}$ birth and parity was consistently and significantly lower among women who lost their previous births than those whose their previous births were alive at the time of pregnancy. Also, the hazard of births progression reduces with increasing in age of woman for the first four births but increases as the women get older for parities higher than four. The reverse pattern was observed for age at first birth.

Table 2 Hazard rate of births progression of married women according to socio-demographic characteristics

\begin{tabular}{|c|c|c|c|c|c|c|c|}
\hline \multirow{3}{*}{$\begin{array}{l}\text { Background } \\
\text { characteristics }\end{array}$} & \multicolumn{7}{|c|}{ Births Progression } \\
\hline & $M-I^{\text {st }}$ & $1^{\text {st }}-2^{\text {nd }}$ & $2^{\text {nd }}-3^{\text {rd }}$ & $3^{\text {rd }}-4^{\text {th }}$ & $4^{\text {th }}-5^{\text {th }}$ & $5^{\text {th }}-6^{\text {th }}$ & $6^{\text {th }}-7^{\text {th }}$ \\
\hline & $\overline{\mathrm{HR}}$ & HR & $\mathrm{HR}$ & $\mathrm{HR}$ & $\mathrm{HR}$ & HR & $\mathrm{HR}$ \\
\hline \multicolumn{8}{|l|}{ Education } \\
\hline None (Ref. Cat.) & 1.000 & 1.000 & 1.000 & 1.000 & 1.000 & 1.000 & 1.000 \\
\hline Primary & $0.95 I^{* * * * *}$ & $0.939 * *$ & 0.972 & 1.011 & I.070**** & $1.12 I^{*} *$ & $1.160 * *$ \\
\hline Secondary & 1.028 & $0.945^{* * * *}$ & 0.939*** & $0.915^{* * * *}$ & $0.903 * * *$ & $0.857^{* * *}$ & 0.854 **** \\
\hline Higher & $1.123^{*} *$ & 1.015 & 0.923 & $0.885^{* * * *}$ & $0.747 * * * *$ & $0.685^{*}$ & $0.565 *$ \\
\hline \multicolumn{8}{|l|}{ Residence } \\
\hline Urban (Ref. Cat.) & 1.000 & 1.000 & 1.000 & 1.000 & 1.000 & 1.000 & 1.000 \\
\hline Rural & 0.996 & 0.996 & 1.000 & 1.026 & 1.036 & 1.056 & 1.081 \\
\hline \multicolumn{8}{|l|}{ Religion } \\
\hline Catholic (Ref. Cat.) & 1.000 & 1.000 & 1.000 & 1.000 & 1.000 & 1.000 & 1.000 \\
\hline Other Christians & 0.992 & 0.969 & 0.974 & 0.989 & 0.960 & 0.922 & 0.933 \\
\hline Islam & 0.966 & 0.976 & 0.988 & 1.034 & 1.063 & 1.079 & 1.156 \\
\hline Traditional & 0.994 & 0.991 & 0.969 & 0.962 & 0.999 & 1.066 & 1.119 \\
\hline Others & 1.080 & 0.910 & 0.912 & 0.872 & 1.003 & 0.809 & 0.691 \\
\hline \multicolumn{8}{|l|}{ Ethnicity } \\
\hline Hausa (Ref. Cat.) & 1.000 & 1.000 & 1.000 & 1.000 & 1.000 & 1.000 & 1.000 \\
\hline Igbo & 0.978 & 1.101 & 1.096 & $1.165 * * *$ & 1.132 & 1.077 & 0.998 \\
\hline Yoruba & I.095*** & 0.963 & 0.949 & 0.903 & $0.820 * *$ & $0.682^{*}$ & $0.577^{*}$ \\
\hline Others & 1.017 & 0.982 & 0.969 & 0.996 & 1.014 & 1.009 & 0.986 \\
\hline \multicolumn{8}{|c|}{ Number of times married } \\
\hline Once (Ref. Cat.) & 1.000 & 1.000 & 1.000 & 1.000 & 1.000 & 1.000 & 1.000 \\
\hline $\mathrm{I}+$ & 1.022 & $0.927^{* *}$ & $0.932 * *$ & $0.924 * *$ & $0.922 * *$ & $0.910 * *$ & $0.917^{* * * *}$ \\
\hline
\end{tabular}


Wealth Quintile

\begin{tabular}{|c|c|c|c|c|c|c|c|}
\hline Poorest (Ref. Cat.) & 1.000 & 1.000 & 1.000 & 1.000 & 1.000 & 1.000 & 1.000 \\
\hline Poorer & 0.979 & 1.018 & 1.025 & 1.044 & 1.052 & 1.069 & I.100**** \\
\hline Middle & 0.991 & 1.025 & 1.032 & 1.028 & 1.058 & 1.054 & 1.068 \\
\hline Richer & 1.021 & 1.050 & 1.053 & 1.037 & 1.020 & 1.026 & 1.029 \\
\hline Richest & 1.035 & I.08I**** & 1.080 & 1.029 & 0.948 & 0.862 **** & $0.796 * *$ \\
\hline \multicolumn{8}{|l|}{ Region } \\
\hline North C (Ref. Cat.) & 1.000 & 1.000 & 1.000 & 1.000 & 1.000 & 1.000 & 1.000 \\
\hline North East & $0.945^{* * * *}$ & $1.104 *$ & $1.110 *$ & $1.167^{*}$ & $1.192 *$ & $1.268^{*}$ & $1.319 *$ \\
\hline North West & 0.982 & I.069**** & 1.046 & I.084**** & $1.093 * * * *$ & I.|4I**** & I.167**** \\
\hline South East & 0.953 & 1.037 & 1.059 & 1.090 & 1.160 & 1.206 & 1.180 \\
\hline South South & 0.985 & $1.067 * * * *$ & 1.055 & 1.048 & 1.044 & 1.081 & 1.073 \\
\hline South West & 1.027 & 0.952 & 0.940 & $0.94 I$ & $0.875^{* * * *}$ & $0.835^{* * * *}$ & $0.783^{*} * * *$ \\
\hline \multicolumn{8}{|l|}{ Child survival } \\
\hline No (Ref. Cat.) & 1.000 & 1.000 & 1.000 & 1.000 & 1.000 & 1.000 & 1.000 \\
\hline Yes & $0.842^{*}$ & $0.592^{*}$ & $0.622^{*}$ & $0.686 *$ & $0.68 I^{*}$ & $0.707^{*}$ & $0.708^{*}$ \\
\hline Current Age & $0.945 *$ & $0.928^{*}$ & 0.963* & 0.994* & $1.024 *$ & $1.055^{*}$ & $1.083 *$ \\
\hline Age at I ${ }^{\text {st }}$ Birth & $0.00 I^{*}$ & I.079* & I.04I* & I.0II粎 & $0.985^{* * *}$ & $0.96 I^{*}$ & 0.940* \\
\hline -2Loglikelihood & 360064.6 & 324873.7 & 274828.5 & 218095.3 & 165902.6 & 119989.4 & 84638.9 \\
\hline Chi-square & 47052.6 & 4863.866 & 1399.2 & 404.7 & 883.519 & 1719.72 & 2331.7 \\
\hline
\end{tabular}

HR: Hazard Rate; *Significant at 0.1\%; **Significant at I\%; ***Significant at 5\%; Ref. Cat.; Reference Category

In Figure 3, the data show that the pattern of hazard of passing through an interval as regards level of education was similar when socio-demographic characteristics were used and not used as control. From the figure, it is clear that the hazard rate of progressing to first birth after marriage was higher among women with higher education than those with lower level of education even when socio-demographic variables were used as control. However, the hazard rate from first to second birth was approximately the same across all the different categories of level of education and the gap was closer when other variables were used as control (Figures 3b, 3i).

From the second to higher order births, the data show that clear disparity exist between hazard rates across the categories of level of education. Consistently, at births orders higher than two, the hazard rate was lower among married women with secondary and higher education than those with either primary or no education irrespective of whether sociodemographic variables were used as control or not (figures 3c-3f; 3j-3n). It is important to know that the hazard rate of married with primary education was higher than their counterparts with no formal education for third, and higher order births when sociodemographic variables were used as control (figures $3 \mathrm{~d}, 3 \mathrm{e}, 3 \mathrm{f}, 3 \mathrm{~g}$ ) but a reverse pattern was observed when only education was used in the model (figures $3 \mathrm{k}, 3 \mathrm{I}, 3 \mathrm{~m}, 3 \mathrm{n})$. 
Figure 3: Hazard function of patterns of birth according to levels of Education without (3a$3 \mathrm{~g}$ ) and with control (3h-3n) for potential confounding variables: NDHS, 2008

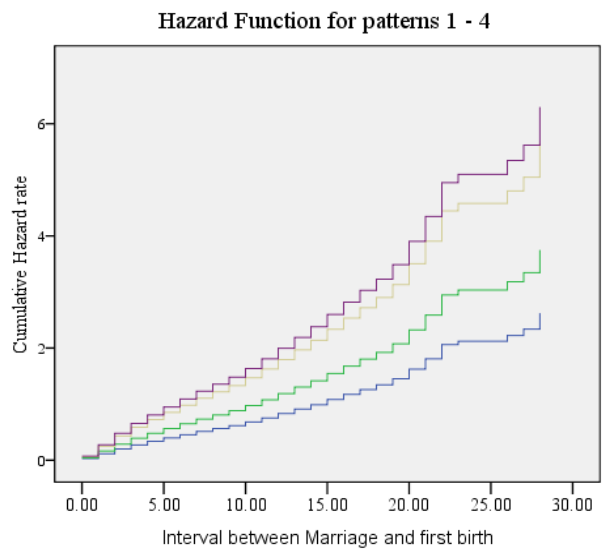

$3 a$

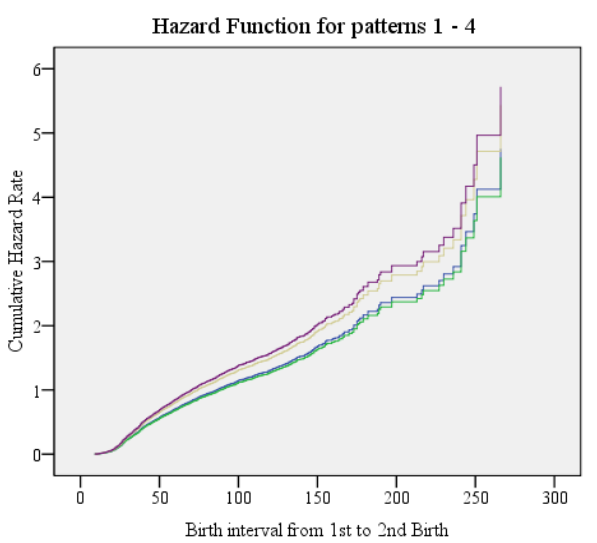

$3 b$

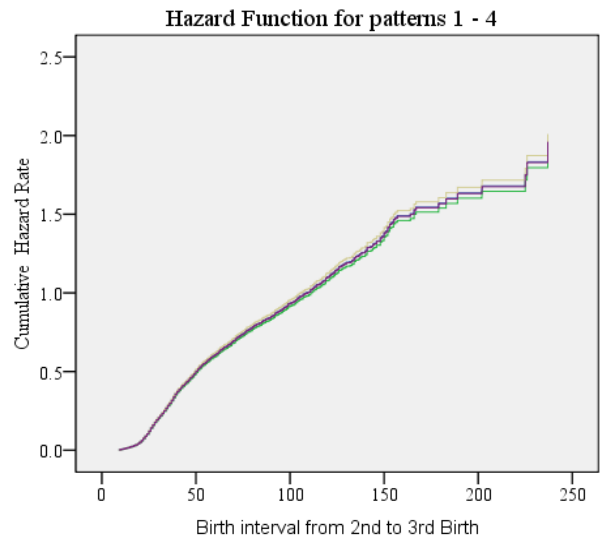

$3 c$

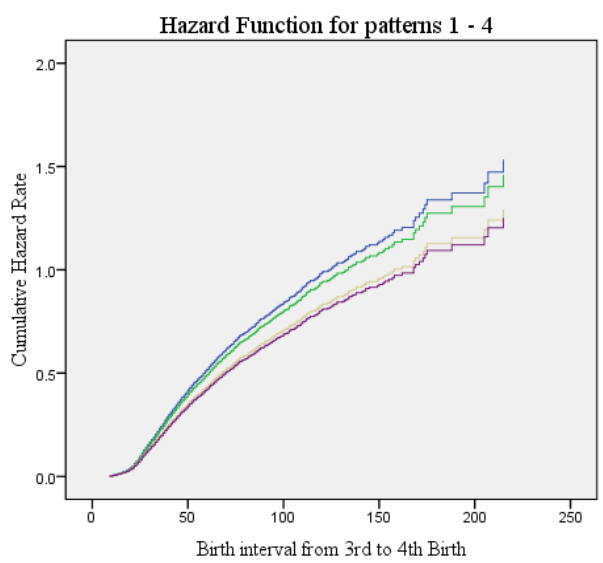

Hazard Function for patterns 1 - 4
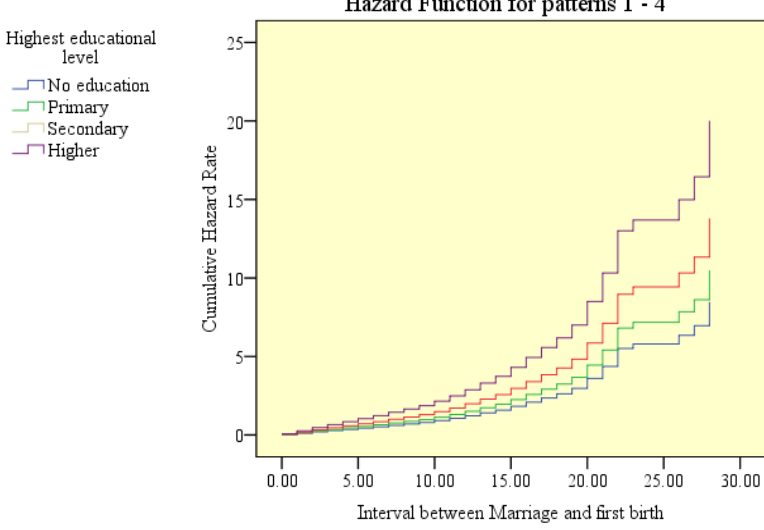

Highest educational
level

$\neg$ No education

$\neg$ Primary

$\longrightarrow$ Secondary

$\neg$ Higher

$3 h$

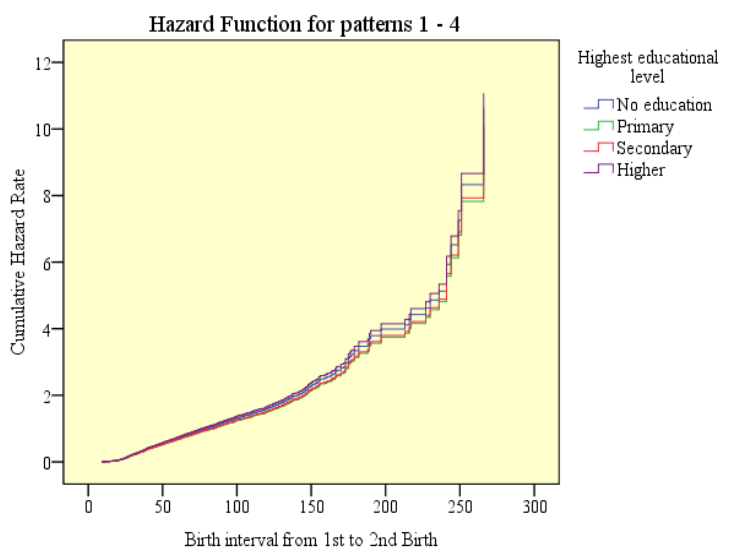

$3 i$
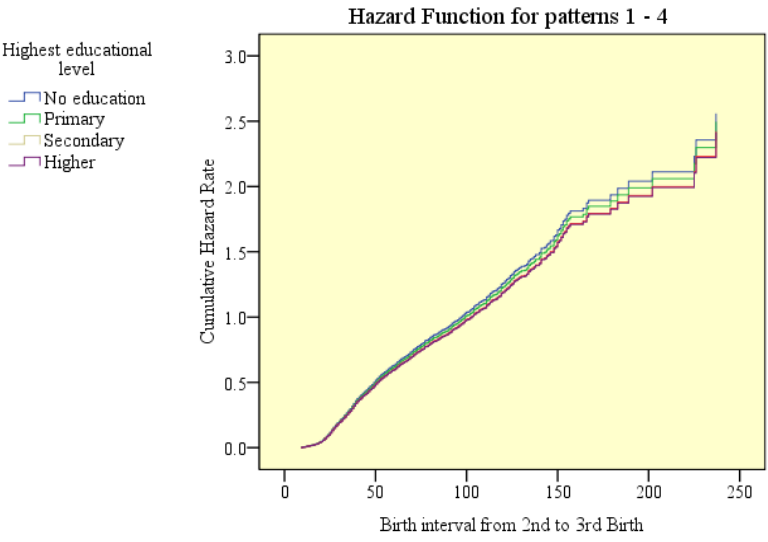

Highest educational $\neg$ No education $\neg$ Primary $\neg$ Secondar $\neg$ Higher

$3 j$

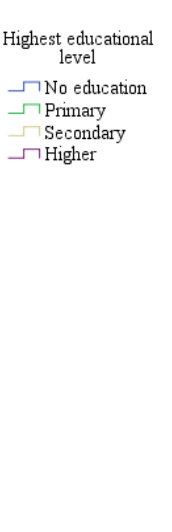

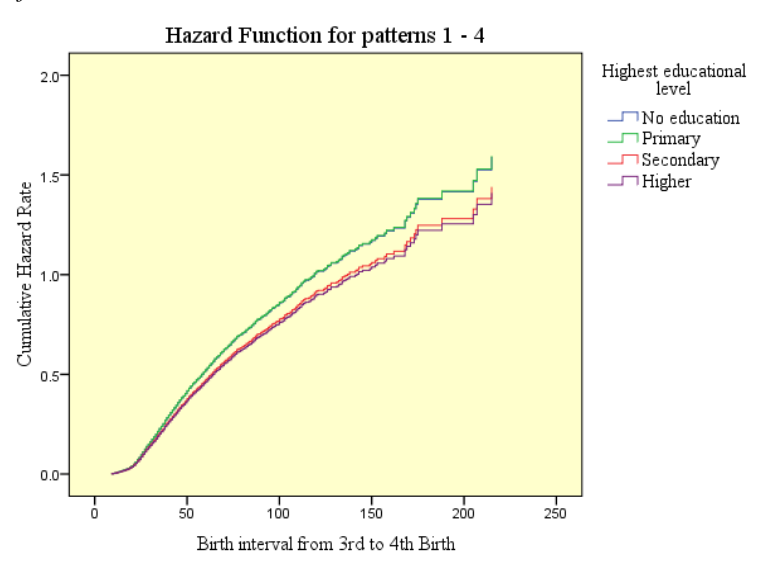


$3 k$

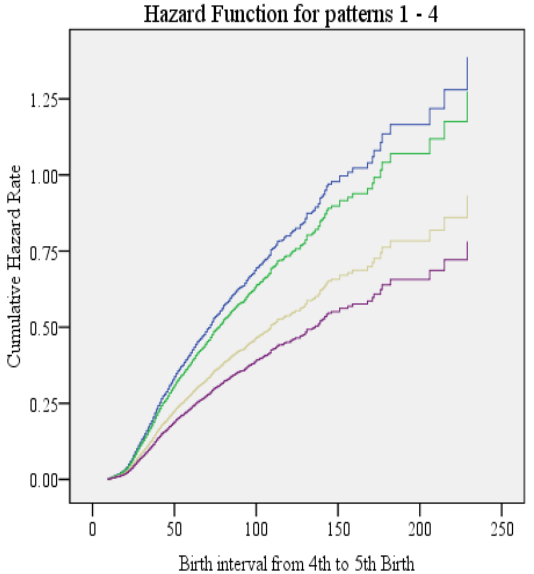

$3 e$

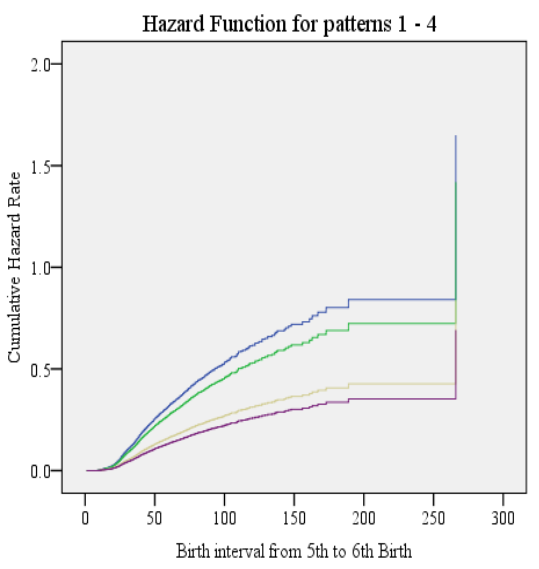

$3 f$

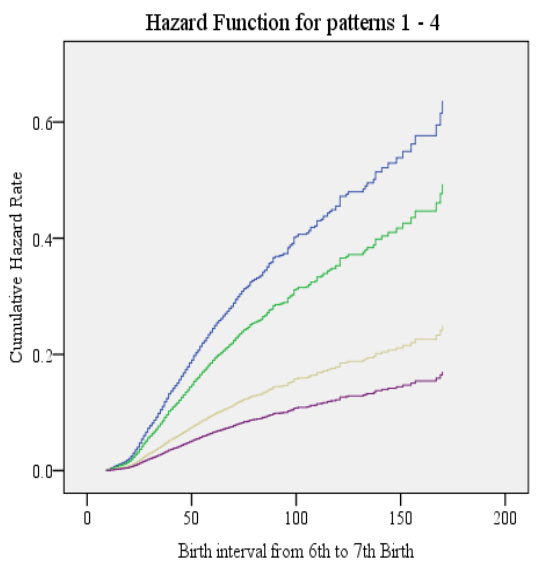

$3 g$

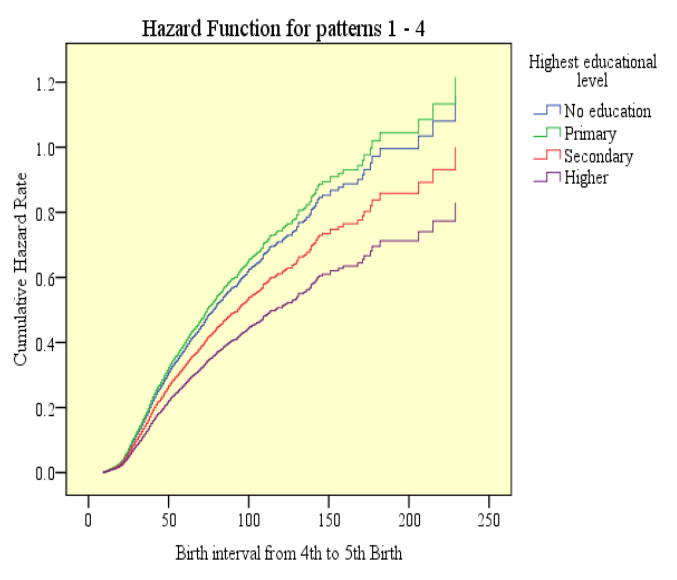

$3 l$

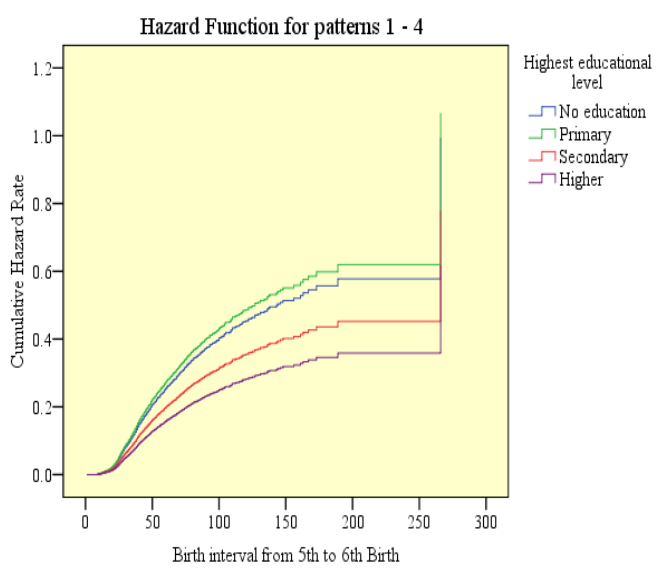

$3 m$

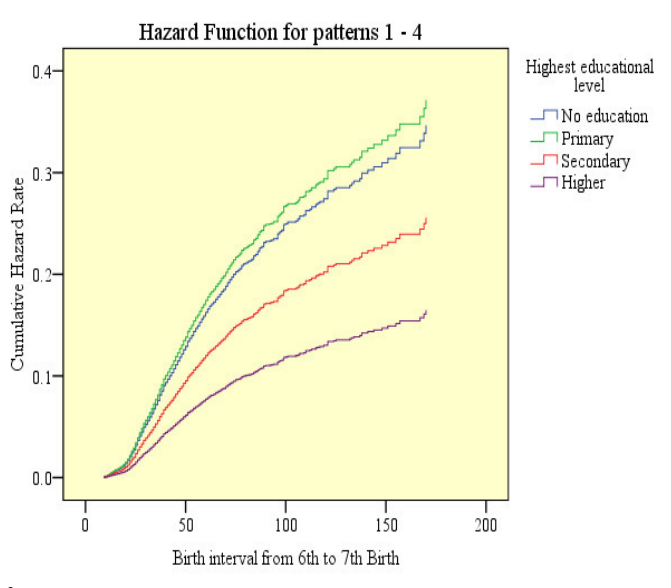




\section{Discussion}

Childbearing is the process of becoming and being pregnant with and giving birth to children. It is often referred to as parturition. The dynamics of childbearing as explored in this study includes, the timing of birth after marriage, how women proceed to higher order births and the interval left between two successive births. In this study we established the role of education in pattern of childbearing by linking it with the timing of each birth. The purpose was to gain additional insight into how the women's level of education in Nigeria interacts with the timing of childbearing. We also examined the differential of childbearing behavior across some socio-demographic characteristics.

The study revealed that the mean CEB reduces with increasing level of education. The mean interbirths interval increases as the level of education increases. The completed fertility of women who had no formal education was higher than those with higher level of education. These outcomes are consistent with the recent in India and Uganda where it was reported that higher education could bring the reduction in fertility rate (Anu and Praveen, 2013; Edward and Paul, 20I I). Possible explanation for this is postponement in age at first marriage among higher educated women and also interest to acquire more education can make a woman to leave longer intervals between two successive births. In Korea, for example, a study by Bumpass and colleagues found that better educated women have shorter second birth intervals than those less educated (Bumpass et al., 1986). Also, in 38 of 5 I countries with DHS data, women with no education were more likely than educated women to have shorter birth intervals (Setty-Venugopal and Upadhyay, 2002). However, it is important to note that the hazard rate of progressing to first birth after marriage found in our study was higher among women with higher education than those with lower education even when socio-demographic variables were used as control.

Child spacing can be said to be improving in Nigeria as found in this study which show that about two-fifth of the studied women left between 24 and 35 months interval between two consecutive births. However, previous findings showed that birth spacing for less than three years can have tremendous health hazards to the mothers and their children (Conde-Agudelo, 2002, Rutstein, 2003). It was argued that for mothers, it can increase the risk of maternal death, trimester bleeding, anaemia, premature rupture of membranes, puerperal endometritis and malnutrition while for children it increases the risk of fetal death, preterm death, low birth weight, small for gestation age, neonatal death, stunting and underweight (Conde-Agudelo, 2002, Rutstein, 2003). Our study further shows that the mean birth interval was higher among older cohort of women than the younger cohorts. This is expected since all births were pulled together in this study and older women are likely to have higher number of children than the younger ones and there is tendency for leaving wider gap between births for higher parity women.

Another variable associated with birth interval and parity progression probability found in this study was the survival of the preceding child. The multivariate analysis revealed that the hazard of births progressing was consistently higher among women who have lost their previous births. This finding corroborates outcome of previous studies in Bangladesh and Tanzania (Chakraborty et al., 1996; Mturi, 1997). Shorter births interval among women who lost their previous child might result from couple's deliberate plan to have a new pregnancy in anticipation of replacing the lost child. Also, the death of a child cuts short nursing durations which results in earlier resumption of sexual intercourse, menstruation and ovulation.

We further found that the completed fertility was highest in the North West and least in the south west where the mean birth interval was highest. Hazard rate of parity progression from second to third and higher order births was higher in the North East and North West but lower in the South West when compared with women in the North Central. The least hazard rate of parity progression and completed fertility in the South West may not be accidental as the region is known to be the more educated, higher prevalence of modern contraceptive use, lower childhood mortality than any other regions in Nigeria (National Population Commission and ICF Macro. 2009; NPopC, 2006). These indices are known in the literature as having influence on births interval, completed fertility and parity progression probability (Adebowale et al., 2011; Hosseini-Chavoshi, 2007. The South-West region in Nigeria consists predominantly of Yoruba ethnic group, while Hausa's are mostly found in the North and lgbo in the East. This study showed that the hazard of short birth interval was least among Yoruba ethnic group than any other religious groups in Nigeria. This reflects in the mean birth interval and completed fertility of Yoruba women which was strikingly higher and lower respectively than the estimates for their Hausa and lgbo counterparts.

Our study also found that higher birth intervals and lower completed fertility were reported among the urban women and richest wealth quintiles. According to religion, the pattern of births interval 
was similar among the catholic women and Muslim women but differs between the Muslims and women in other Christian religious denomination. The completed fertility was highest among Muslim women in Nigeria. Differential in fertility across religious group was found in previous studies. For instance, Westoff and Frejka (2007) in their study among European countries found that Muslim fertility in 13 of these countries was found to be higher than that for other women, but in most countries with trend data, the differences are diminishing over time. Also, in Lutz (1987), it was established that the Arab countries, culture and religion tend to have strong positive effects on fertility. Across cultures, Catholicism has a fertility-increasing effect like the effect of all religions except Islam (Lutz, 1987). Also, shrinking pattern of fertility differentials among religious groups was found in Li study (Li, 2008).

\section{Conclusion}

Fertility and birth progression rates as found in this study are high especially, among married women with either no or primary education. Socio-demographic factors found to be related to childbearing progression included; education, ethnicity, wealth quintile, survival of the preceding child, age at first birth, region and number of union. Existing policies addressing females' education should be sustained and Government should intensify campaign on the need for spacing and limiting birth particularly in the North East and North West. This will have tremendous effect on reducing the pace of population growth and fertility in Nigeria. It will also be beneficial to women of childbearing age and under-five children in terms of their health and survival chances.

\section{Limitation}

The childbearing progression was based on report by women at the time of the study; therefore the report may slightly differ from the true situation as a result of memory lapses with respect to the timing of childbearing. It is therefore suggested that Nigerian Government should channel resources towards improving its vital registration system. Follow-up studies that involve newly married women can also limit the errors associated with reporting of births in a cross-sectional survey if the present form of birth registration system in Nigeria remains the same. A need for caution in interpreting the observed relationship between female education and fertility as causal is essential (Bledsoe et. al., 1999). A negative association as found in the current study may arise due to omitted variables, such as individual ability or household and community resources, which affect both schooling and fertility decisions.

\section{Competing interests}

The authors declare that they have no competing interests.

\section{Acknowledgements}

The authors thank the National Population Commission and ICF Macro Calverton, Maryland, USA for releasing the data for this study.

\section{References}

Adai, I. 1999. Ethnicity and contraceptive use in subSaharan Africa: The Case of Ghana, Journal of Biosocial Science, 3I (I): I05-I 20

Adebowale, S.A, Fagbamigbe FA, Bamgboye EA. 20I I. Contraceptive use: implication for completed fertility, parity progression and maternal nutritional status in Nigeria. Afr J Reprod Health. 20I I Dec; I5(4):60-7.

Alaka, M.B. 2002. Why does Education Lead to Lower Fertility? A Critical Review of Some of the Possibilities. World Development Vol. 30, No. 10, pp. 1779-1790, 2002

An-Magritt, J. 2010. Fertility and Poverty: The Role of Gender and Reproductive Health. Povpov Research Network

Ann M. Veneman. 2007. Education Is Key to Reducing Child Mortality: The Link Between Maternal Health and Education. UN Chronicle, Volume XLIV Number 4, 2007

Anu Nag and Praveen Singhal. 2013. Impact of Education and Age at Marriage on Fertility among Uttar Pradesh Migrants of Ludhiana, Punjab, India. Anthropologist, I5(2): 225-230 (2013)

Baschieri $A$ and Hinde A. 2007. The proximate determinants of fertility and birth intervals in Egypt: An application of calendar data. Demographic Research: Volume 16, Article 3

Bbaale Edward and Mpuga Paul. 20I I. Female Education, Contraceptive Use, and Fertility: Evidence from Uganda. Consilience: The Journal of Sustainable Development Vol. 6, Iss. I, Pp. 20-47

Becker, Gary S. 1982. A Treatise on the Family.Enlarged Edition. Cambridge: Havard Univ.Press.

Becker, Gary S. 1974. "A theory of Social Interactions," Journal of Political Economy 82 (6): 1063-93

Bhardwaj, S.B, Sharma, G.C and Arun Kumar. 2010. Analysis of The Parity Progression Ratios. Journal of Reliability and Statistical Studies. Vol. 3, Issue I(20I0): 37-4I

Bicego and Ahmad, (1996). Potential Effects on Fertility and Child Health and survival of BirthSpacing, Preferences in sub-Saharan Africa. 
Studies in Family Planning.3 I (2),99-I I 0.

Bledsoe $\mathrm{CH}$, Casterline JB, Johnson-Kuhn JA, and Haaga JG. 1999. Critical Perspectives on Schooling and Fertility in the Developing World. Committee on Population Commission on Behavioral and Social Sciences and Education National Research Council. National Academy Press Washington, D.C.

Bongaarts, J (1978).A framework for analyzing the proximate determinants of fertility.Population and Development Review, vol.4, No. I, pp. 105132.

Bumpass, L.L, Ronald R.R, and Palmore, J.A. 1986."Determinants of Korean birth intervals: The confrontation of theory and data" Pop. Stud.Vol.40:403-423.

Caldwell, J.C. 1980. Mass education as a determinant of the timing of fertility decline. Population and Development Review, 6(3), 225255.

Caldwell, J.C. 1982. Theory of Fertility Decline. London: Academic Press.

Chakraborty. R,Nitai. S and Ataharul, M. 1996."Differential Pattern of birth intervals in Bangladesh".Population Studies, Vol.28(2):277297.

Coale, A. 1973."The Demographic transition”.In International Population Conference, vol.i, edited by IUSSP. Liege, Belgium:IUSSP.

Cochrane, S. H. (1979). Fertility and Education. What do we really know? Baltimore, Maryland: Johns Hopkins University Press.

Conde-Agudelo,A. 2002. Association between interpregnancy intervals and Maternal/Patrnal Outcomes in Latin America. OBSI regional Washington D.C

Davis, K and Blake, J. 1956. "Social Structure and Fertility: An analytical framework." Economic Development and Cultural Change 4:2 I I-35.

Dewit, M.L. and RajultonF. 1992. Education and timing of parenthood among Canadian women: a cohort analysis, Social Biology 39 (I-2): 109-22.

Easterlin, R.A. 1978. Towards a socioeconomic theory of fertility. In Fertility and Family Planning: A world view, ed. S.J. Behrman, L.Corsa and R. Freeman. University of Michigan Press.

Feeny, Griffith and Wijeyesekera, M. 1983. Parity progression and birth interval analysis in South Asia. Paper presented at the Conference on Recent Population Trends in South Asia, New Delhi.

Grieser, M; et al. 200I. Reproductive decision making and the HIV/AIDS Epidemic in Zimbabwe.Journal of Southern Africa Studies, Vol. 27 pp 225-243.

Hawthorn, (1968).Effect of time-out release contingencies on changes in child.Forehand, R. Child non-compliance to parent commands. Behavioural analysis and treatment.

Henry, L. 1972. On the Measurement of Human Fertility. Amsterdam: Elsevier.

Ho, SS. 1994. Teenage childbearing, family size and birth interval: a study in Singapore. Public Health. 1984 Nov;98(6):336-43.

Hossain, S.Z. 1989. Effect of female education on the proximate determinants of fertility in Bangladesh. Rural Demogr. 1989; 16(I-2):3I-4I.

Hosseini-Chavoshi M, McDonald P,Abbasi-Shavazi M.J. 2007.Fertility and contraceptive use dynamics in Iran: Special focus on low fertility regions.ADSRI Working Paper I

UNDP. 20I0. Human Development Index. Human Development Reports. United Nations Development Programme 2010.

Kasarda, J.D, Billy, J.O, West, K. I 986. Status Enhancement and Fertility: Reproductive responses to social mobility and educational Opportunity. NewYork:Academic press.

Khan, Mehrab, A and Mizanur. 1997. Determinants of contraceptive methods choice in rural Bangladesh, Asia-Pacific Population Journal I 2 (3):65-83.

Konia T. Kollehlon. 2003. Ethnicity and fertility in Nigeria. Biodemography and Social Biology Volume 50, pages 20I-22I

KritiVikram, Sonalde Desai, Reeve Vanneman. 201 I. Maternal Education and Child Mortality: Exploring the Pathways of Influence. A paper presented at Population Association of America meeting in Washington DC.

Lesthaeghe and Surkyn.1988. The socio-economic determinants of fertility. In Reproductive change in developing countries: Insights from the WFS, ed. J. Cleland and Hobcraft J: Oxford Uni. Press. The end of world population growth. Nature, Vol. 412 pp, 543 - 546.

$\mathrm{Li}, \mathrm{Z}$. 2008. Religious affiliation, religiosity, and male and female fertility. Demographic Research: Volume 18, Article 8, Pages 233-262

Lutz W. 1987. Culture, religion, and fertility: a global view. Genus. 1987 Jul;43(3-4): 15-35.

Maternal Mortality and Morbidity associated with interpregnancy interval: (Clinical Research Ed.), Vol.32I (727I): I 255-I 259.

Maxwell, N.L. 1987. The influences on the timing of first childbearing, Contemporary Political Issues 5:113-122.

Mturi, A.J. 1997. "The determinants of birth intervals among non-contracepting Tanzanian women." African Population Studies, Vol. I2(2).

National Population Commission and ICF Macro. 2009. Nigeria Demographic and Health Survey 
2008. Abuja, Nigeria: National Population Commission and ICF Macro.

National Population Commission. 2004. National policy on population for sustainable development. Abuja, Nigeria: National Population Commission.

Norton, M. 2005. New evidence on birth spacing: Promising findings for improving newborn, infant, child, and maternal health. International Journal of obstretrics and Gynecology.89, SI-S6 Journal Biosocial Science

Ntozi, J.P.M and Ahimbisibwe, F.E. 200I. Prospects for fertility decline in the face of HIV/AIDS in Uganda. Paper presented at the United Nations Secretariat Workshop on Prospects for Fertility Decline in High Fertility Countries, New York, July 9-II.

PRB, 2012. Population Reference Bureau.World Population Datasheet 2012 edition focus on noncommunicable diseases.

Rajulton, Fernando, Balakrishan, T.R. 1988. Age at first birth in Canada: A hazard model analysis, Genus 44:53-72.

Rosenzweig, Mark R \& Schultz, T Paul, 1985. "The Demand for and Supply of Births: Fertility and Its Life Cycle Consequences," American Economic Review, American Economic Association, vol. 75(5), pages 992-1015, December.

Rosenzweig, Mark R \& Schultz, T Paul, 1989. "Schooling, Information and Nonmarket Productivity: Contraceptive Use and Its Effectiveness," International Economic Review, Department of Economics, University of Pennsylvania and Osaka University Institute of Social and Economic Research Association, vol. 30(2), pages 457-77

Lam, David, and Suzanne Duryea. 1999. "Effects of Schooling on Fertility, Labor Supply, and Investments in Children, with Evidence from Brazil." The Journal of Human Resources, 34(I): 160-192.

McQuillan Kevin. 2004. When Does Religion Influence Fertility? Population and Development Review. Vol. 30, No. I (Mar., 2004), pp. 25-56

Rutstein, S.O. 2000. Effect of birth intervals on mortality and health: Multivariate cross country analyses. Unpublished presentation to USAID,
Washington, D.C.,July.

SajedaA, Casterline J.B, and Laura, S. 2007. Poverty and Fertility: Evidence and Agenda. The Population Council, Inc.Working paper number 4. ISSN: I554-8538

Schultz, T.P. (198I), Economics of Population, Reading, MA: Addison-Wesley.

Samuel Yohannes, Mekitie Wondafrash, MulumebetAbera and EshetuGirma. 2011. Duration and determinants of birth interval among women of child bearing age in Southern Ethiopia. BMC Pregnancy and Childbirth 201 I, I I:38

Shamsudeen Usman. 2010. Insights into the state of the Nigerian economy by hon. Minister, national planning commission presented at Bayero University, Kano state November 042010

Setty-Venugopal, V and Upadhyay U.D. 2002. Birth Spacing: Three to five saves lives. Population Reports, Series L, No. I3. Baltimore: John Hopkins Bloomerg School of Public Health, Population information Program.

Udjo Eric O. 1997. Journal of Tropical Pediatricstropej.oxfordjournals.org. The Effect of Child Survival on Fertility in Zimbabwe: A Micromacro Level Analysis. J Oxford Journals Medicine Journal of Tropical Pediatrics (1997) 43 (5): 255266.

UNAIDS. 20I I. Global HIV/AIDS response. Epidemic update and health sector progress towards Universal Access. 20I I Progress Report

United Nations. 1995a. The world's women 1995: Trends and statistics. New York, United Nations. Social Statistics and Indicators Series K, No. 12.

United Nations. 1995b. Women's education and fertility behaviour: recent evidence from the demographic and health surveys. ST/ESA/SER.R/ 137.

Westoff, Charles F. 1992. Age at marriage, Age at first birth and fertility in Africa. World bank Technical Paper Number 169. Washington, D.C: The World Bank.

Westoff C.F and Frejka T. 2007. Religiousness and Fertility among European Muslims. Population and Development Review. Vol. 33, No. 4 (Dec., 2007), pp. 785-809. 